\title{
Changes in water and sugar-containing beverage consumption and body weight outcomes in children
}

\author{
Rebecca Muckelbauer ${ }^{1 *}$, Steven L. Gortmaker ${ }^{2}$, Lars Libuda ${ }^{3,4}$, Mathilde Kersting ${ }^{5}$, Kerstin Clausen ${ }^{6}$, \\ Bettina Adelberger ${ }^{1}$ and Jacqueline Müller-Nordhorn ${ }^{1}$ \\ ${ }^{1}$ Institute of Public Health, Charité - Universitätsmedizin Berlin, Seestr. 73, 13347 Berlin, Germany \\ ${ }^{2}$ Department of Social and Behavioral Sciences, Harvard T.H. Chan School of Public Health, 677 Huntington Avenue, Boston, \\ MA 02115, USA \\ ${ }^{3}$ Department of Child and Adolescent Psychiatry, University Hospital Essen, University of Duisburg-Essen, Virchowstr. 174, \\ 45147 Essen, Germany \\ ${ }^{4}$ Research Institute for the Prevention of Allergies and Respiratory Diseases in Childhood, Department of Pediatrics, \\ Marien-Hospital Wesel, Pastor-Janßen-Str. 8-38, 46483 Wesel, Germany \\ ${ }^{5}$ Research Institute of Child Nutrition, University of Bonn, Heinstück 11, 44225 Dortmund, Germany \\ ${ }^{6}$ Center of Excellence for Nutrition, Hofer Str. 20, 95326 Kulmbach, Germany
}

(Submitted 30 October 2015 - Final revision received 10 February 2016 - Accepted 26 February 2016 - First published online 4 April 2016$)$

\section{Abstract}

An intervention study showed that promoting water consumption in schoolchildren prevented overweight, but a mechanism linking water consumption to overweight was not substantiated. We investigated whether increased water consumption replaced sugar-containing beverages and whether changes in water or sugar-containing beverages influenced body weight outcomes. In a secondary analysis of the intervention study in Germany, we analysed combined longitudinal data from the intervention and control groups. Body weight and height were measured and beverage consumption was self-reported by a 24-h recall questionnaire at the beginning and end of the school year 2006/ 2007. The effect of a change in water consumption on change in sugar-containing beverage (soft drinks and juices) consumption, change in BMI $\left(\mathrm{kg} / \mathrm{m}^{2}\right)$ and prevalence of overweight and obesity at follow-up was analysed using regression analyses. Of 3220 enroled children, 1987 children (mean age 8.3 (sD 0.7 ) years) from thirty-two schools were analysed. Increased water consumption by 1 glass/d was associated with a reduced consumption of sugar-containing beverages by 0.12 glasses/d $(95 \%$ CI $-0 \cdot 16,-0 \cdot 08)$ but was not associated with changes in BMI $(P=0.63)$. Increased consumption of sugar-containing beverages by 1 glass/d was associated with an increased BMI by 0.02 (95\% CI $0.00,0.03) \mathrm{kg} / \mathrm{m}^{2}$ and increased prevalence of obesity (OR 1.22; $95 \%$ CI 1.04, 1.44) but not with overweight $(P=0 \cdot 83$ ). In conclusion, an increase in water consumption can replace sugar-containing beverages. As sugar-containing beverages were associated with weight gain, this replacement might explain the prevention of obesity through the promotion of water consumption.

Key words: Water consumption: Soft drinks: Juices: BMI: Overweight and Obesity: Children

Water is the recommended beverage for children as well as for adults according to several dietary recommendations ${ }^{(1-5)}$. In contrast to sugar-containing beverages, the consumption of water does not add to dietary energy intake. Thus, drinking water instead of sugar-containing beverages is a recommended dietary behaviour to prevent overweight and obesity in children ${ }^{(6-8)}$.

The beverage category 'sugar-containing beverages' includes soft drinks with added sugars ('sugar-sweetened beverages') as well as fruit juices. Sugar-sweetened beverages are claimed to be the food group with the strongest evidence for a causal link to an increased risk for obesity in children ${ }^{(9)}$. Recent reviews and metaanalyses concluded that reducing their consumption can prevent weight gain in children ${ }^{(10-12)}$. Several national and international dietary guidelines recommend reducing or limiting the consumption of sugar-containing beverages in children ${ }^{(5,13-15)}$.
The consumption of fruit juices, which can contain a comparable amount of sugar with soft drinks, is recommended but should also be limited to 2 servings/d in school-aged children according to the American Academy of Pediatrics ${ }^{(16)}$.

Water as a beverage may replace the consumption of sugarcontaining beverages, and thereby reduce energy intake and weight gain. In experimental trials on adults, the consumption of water instead of sugar-containing beverages reduced total energy intake with the subsequent meal in the short-term, especially in older adults as indicated in systematic reviews $^{(17,18)}$. In children, only a few such experimental studies have been conducted so far ${ }^{(19)}$. One study showed that drinking water before a meal instead of sugar-containing beverages reduced total energy intake in the short-term ${ }^{(20)}$ while another did not ${ }^{(21)}$. One recent review identified several intervention 
studies indicating that the replacement of energy-containing beverages with water can reduce weight gain in children ${ }^{(19)}$.

However, the evidence for a beneficial effect of an absolute increase in water consumption for overweight and obesity prevention is scarce as shown by recent systematic reviews in adults $^{(22)}$ and children ${ }^{(23)}$. Three longitudinal studies ${ }^{(24-26)}$ and one randomised intervention trial ${ }^{(27)}$ indicate that increased water consumption could support weight loss in adults dieting for weight loss. In children, two out of three longitudinal observational studies $^{(28-30)}$, one quasi-experimental study ${ }^{(31)}$ and one controlled intervention study ${ }^{(32)}$ indicated a beneficial effect of increased water consumption on body weight outcomes. In the two intervention studies, water consumption was increased by the provision of water fountains in schools ${ }^{(31,32)}$. In the quasi-experimental study ${ }^{(31)}$, the school intervention reduced the BMI and the likelihood for being overweight, which could be explained by the observed reduction in milk purchases in the schools.

In the controlled intervention study ${ }^{(32)}$, the promotion of water consumption in schools reduced the risk of overweight. Children in the intervention group drank 1 glass of water/d more than children in the control group. However, the decreased consumption of sugar-containing beverages did not reach significance between the groups. As the intervention effect was tested by the comparison of the intervention and control group, the pathway whereby changes in water and sugar-containing beverage consumption affected weight development at the individual level remained open to investigation.

In a secondary analysis of this intervention study, we combined longitudinal data from the intervention and control group to investigate within-subject effects. The aim was to investigate in this larger, combined sample how the consumption of water and sugar-containing beverages affected body weight outcomes in children. We tested whether an individual change in water consumption during 1 school year was associated with a change in sugar-containing beverage consumption, and if a change in the consumption of water or sugar-containing beverages was associated with a change in body weight outcomes. In addition, we looked at the two subcategories of sugar-containing beverages, soft drinks and juices, separately, and investigated whether these associations differed by sex, body weight category or migrational background of the children.

\section{Methods}

\section{Study design and population}

We conducted a secondary analysis of an intervention study by combining children in the intervention and control groups and analysing them as a longitudinal study, while controlling for the intervention. The primary aim of the intervention study was to investigate whether the promotion of water consumption in schoolchildren was effective in preventing overweight ${ }^{(32)}$. The intervention study was an open-label, two-arm, parallel controlled trial, registered at www.clinicaltrials.gov (NCT00554294). This study was conducted according to the guidelines laid down in the Declaration of Helsinki and all procedures involving human subjects were approved by the Ethics Committee of the Rheinische Friedrich-Wilhelms-Universität Bonn (no. 030/06).
Written informed consent was obtained from all subjects. Details and results of the intervention study have been provided elsewhere ${ }^{(32-34)}$. Elementary schools were randomly selected from deprived districts of two German cities, Dortmund and Essen. Schools in the city of Dortmund ( $n$ 17) were allocated to the intervention group and schools in Essen ( $n$ 16) were allocated to the control group. The intervention aimed to increase water consumption by providing water fountains on school grounds and educational lessons on water. The lessons were given by teachers who were provided with a booklet and a box of teaching material such as a compact disc with a song. Control schools did not receive any intervention. The intervention period lasted 1 school year from August 2005 to June 2006. In total, 3220 schoolchildren from the second and third grades were enroled. Complete data on body weight measurements at baseline and follow-up were available for 2950 children from thirty-two elementary schools ${ }^{(32)}$. A smaller number of children with a mean age of 8.3 (SD 0.7 ) years additionally had complete baseline and follow-up measures of beverage intake ( $n$ 1987). This population with complete data from both body weight and beverage intake served as the sample for the present analysis.

\section{Measures}

Before the intervention start (baseline) and after the intervention period of 1 school year (follow-up), body weight and height were measured and children filled out questionnaires to determine beverage consumption. Age, sex and migrational background were assessed at baseline. Migrational background was present if the child or at least one parent was born in a foreign country.

Children's body weight and body height were measured in light clothes by trained study staff at baseline and follow-up. BMI was calculated as body weight divided by height squared $\left(\mathrm{kg} / \mathrm{m}^{2}\right)$. Children were categorised by their BMI into normal weight (including underweight), overweight and obese groups considering age and sex according to the recommendations of the International Obesity Task Force ${ }^{(35)}$.

Beverage consumption was assessed by a semi-quantitative, paper-and-pencil, 24-h recall questionnaire ${ }^{(36)}$. In this questionnaire, children were asked how many glasses (defined as about $200 \mathrm{ml} /$ glass) they drank during five defined meals or time intervals within the previous $24 \mathrm{~h}$ of the seven predefined beverage categories. The smallest consumption unit was half a glass/d. The seven beverage categories were as follows: (1) tap water, (2) mineral water, (3) tea (fruit and herbal), (4) milk (including milk drinks), (5) soft drinks (including lemonades and ice tea), (6) juices (including fruit drinks of any percentage fruit juice) and (7) other beverages. The category 'other beverages' provided the children a choice to report beverages they could not allocate to one of the previous categories. The relative validation of the questionnaire with a 24-h weighed record showed good correlations between the two assessment methods with correlation coefficients between 0.8 and 0.9 for the reported volumes in the respective beverage categories ${ }^{(36)}$. Tap and mineral water were combined to the category 'water'. Another measure was created titled 'sugar-containing beverages' that combined intake of soft drinks and juices. Total beverage consumption was calculated by summing up all beverage 
categories. For the analyses, we calculated the change in consumption for each beverage category by subtracting the baseline from the follow-up consumption. In addition, we categorised children by their change in the consumption of water, sugar-containing beverages, soft drinks and juice into quintiles to obtain categorical variables.

\section{Statistical analysis}

For the present analysis, we included only children with complete anthropometric and beverage data at baseline and follow-up. In a missing data analysis, we compared children excluded because of missing data on beverage consumption with the children included with regard to their baseline characteristics using the Wilcoxon's rank sum test for continuous variables and the $\chi^{2}$ test for categorical variables.

In univariate tests, we investigated whether beverage consumption, BMI and the prevalence of overweight and obesity changed from baseline to follow-up by using the Wilcoxon's signed-rank test and the McNemar's test, respectively.

Mixed-effects regression models (PROC GLIMMIX in SAS 9.4) were applied for analyses of the effects of within-subject changes in beverage consumption. In the models, schools were generally treated as a random variable with a compound-symmetry structure to consider the clustered structure of the data. All models were adjusted for potential confounders: age at baseline, sex (male $v$. female), migrational background (yes $v$. no), study arm (intervention $v$. control group) and duration of follow-up (days between individual baseline and follow-up measurement).

For the analyses of the effects of change in water consumption on change in sugar-containing beverages (dependent variable), the basic model was additionally adjusted for baseline BMI, baseline consumption of water and sugar-containing beverages and baseline consumption as well as changes in consumption of the remaining beverage categories - milk, tea and other beverages.

For the analyses of the effects of changes in water and in sugar-containing beverage consumption on change in BMI (dependent variable), the basic model was additionally adjusted for baseline BMI, baseline consumption of the beverage categories and change in consumption of milk, tea and other beverages. Thus, the model for the effect of change in water consumption on BMI was not adjusted for the change in sugarcontaining beverages consumption because we wanted to estimate the total effect of water consumption, including potential effects caused by changes in sugar-containing beverages. Accordingly, the model for sugar-containing beverages was not adjusted for change in water consumption.

To investigate possible non-linear effects of the change in beverage consumption, we also calculated models with categorical variables (quintiles) of change in consumption of water, sugar-containing beverages and the subcategories soft drinks and juices as the independent variables. Effects of the respective quintiles are presented in comparison with the 3rd quintile as the reference category because this category represented no or a small change in beverage consumption.

All models were repeated separately for the subcategories soft drinks and juices in place of the combined category sugarcontaining beverages. We tested whether the effects differed between the intervention and control group by adding the interaction term of the study arm with the respective independent variable (e.g. change in water consumption) to the adjusted models. We also tested whether sex, migrational background, baseline overweight (including obesity) or baseline obesity modified the effect. If the interaction term reached significance, stratified analyses were performed.

The within-subject effects of changed beverage consumption on the prevalence of overweight (including obesity) and obesity (dependent variables) were analysed in separate models through logistic mixed-effects models by adding a logarithmic link for binary data and an underlying binomial distribution. To test the robustness of the logistic model, we built a second model, which adjusted for baseline prevalence of overweight and obesity, respectively, instead of adjusting for baseline BMI. Statistical analyses were performed with SAS 9.4 (SAS Institute Inc.). $P$ values $<0.05$ were considered to be statistically significant.

\section{Results}

\section{Study population}

The present analysis included 1987 children with complete data on body weight measures and beverage consumption at baseline and follow-up. The mean follow-up duration was $250 \mathrm{~d}$ (8.2 months) with an SD of $7 \mathrm{~d}(0.2$ months). Baseline characteristics as well as changes in body weight outcomes and beverage consumption from baseline to follow-up are presented in Table 1. Although mean changes in the consumption of most beverages were small, ranging from -0.1 to 0.6 glasses $/ \mathrm{d}$, the individual changes varied substantially between the children as indicated by a SD ranging from 1.3 to 3.1 glasses/d. Water consumption increased in the overall population (Table 1). Stratification into the two study arms, however, showed that water consumption increased only in the intervention group by an average of 1.2 (SD 3.1) glasses/d $(P<0.001)$ but did not change in the control group $(-0.0$ (SD 2.9$)$ glasses/d, $P=0 \cdot 58$ ). Similarly, the consumption of sugar-containing beverages decreased in the intervention group by 0.2 (sD $2 \cdot 8)$ glasses/d $(P=0 \cdot 019)$, whereas there was no change in the control group (0.0 (SD 2.6) glasses/d, $P=0.67$ ) (data not shown).

\section{Missing data analysis}

A total of 963 children with missing beverage data were excluded from the group of 2950 children with complete data on body weight measures. Characteristics of the included and excluded children are compared in Table 2. The samples were similar with regard to migrational background and body weight measures, whereas they differed slightly with respect to age, sex and study arm allocation.

\section{Effect of changes in water consumption on beverage consumption}

Fig. 1 shows the within-subject changes in beverage consumption by each increase in water consumption by 1 glass/d from baseline to follow-up. The effects are shown 
Table 1. Baseline characteristics and changes over the follow-up period of $250 \mathrm{~d}$ (Numbers and percentages; mean values and standard deviations; $n$ 1987)

\begin{tabular}{|c|c|c|c|c|c|c|}
\hline \multirow[b]{2}{*}{ Characteristics } & \multirow[b]{2}{*}{ Subcategory } & \multicolumn{2}{|c|}{ Baseline } & \multicolumn{2}{|c|}{ Change } & \multirow[b]{2}{*}{$P^{*}$} \\
\hline & & $n$ & $\%$ & $n$ & $\%$ & \\
\hline \multirow{2}{*}{\multicolumn{4}{|c|}{ Age (years) }} & \multicolumn{2}{|c|}{ - } & \multirow{9}{*}{$<0.001$} \\
\hline Mean & & & & & \\
\hline SD & & \multicolumn{2}{|c|}{$\begin{array}{l}8 \cdot 3 \\
0.7\end{array}$} & \multirow{2}{*}{\multicolumn{2}{|c|}{ - }} & \\
\hline Male & & 940 & $47 \cdot 3$ & & & \\
\hline Migrational background & & 874 & $44 \cdot 0$ & \multicolumn{2}{|c|}{-} & \\
\hline Intervention group & & 1070 & 53.9 & \multicolumn{2}{|c|}{ - } & \\
\hline \multicolumn{6}{|l|}{ BMI $\left(\mathrm{kg} / \mathrm{m}^{2}\right)$} & \\
\hline Mean & & \multirow{2}{*}{\multicolumn{2}{|c|}{$\begin{array}{r}17.2 \\
2.9\end{array}$}} & \multicolumn{2}{|c|}{0.4} & \\
\hline & & & & \multirow{2}{*}{\multicolumn{2}{|c|}{$0 \cdot 7$}} & \\
\hline \multirow{5}{*}{ BMI category $\dagger$} & \multirow{5}{*}{$\begin{array}{l}\text { Normal weight } \\
\text { Overweight } \\
\text { Obesity }\end{array}$} & & & & & 0.83 \\
\hline & & 1500 & 75.5 & -7 & -0.4 & \\
\hline & & 345 & $17 \cdot 4$ & 12 & 0.6 & \\
\hline & & 142 & $7 \cdot 1$ & -5 & -0.3 & \\
\hline & & Mean & SD & Mean & SD & \\
\hline \multicolumn{7}{|c|}{ Beverage consumption (glasses/d) $\ddagger$} \\
\hline Water & & 3.2 & $2 \cdot 7$ & 0.6 & $3 \cdot 1$ & $<0.001$ \\
\hline \multirow[t]{3}{*}{ Sugar-containing beverages } & & $2 \cdot 7$ & $2 \cdot 4$ & -0.1 & $2 \cdot 7$ & 0.15 \\
\hline & Soft drinks & 1.3 & 1.7 & -0.0 & $2 \cdot 0$ & 0.35 \\
\hline & Juice & 1.4 & 1.7 & -0.0 & $2 \cdot 0$ & 0.43 \\
\hline Milk & & 1.2 & 1.3 & 0.0 & 1.6 & 0.63 \\
\hline Tea & & 0.6 & $1 \cdot 1$ & $0 \cdot 1$ & 1.4 & 0.027 \\
\hline Other beverages & & 0.3 & 0.9 & 0.2 & 1.3 & $<0.001$ \\
\hline Total beverage consumption & & 8.0 & $3 \cdot 8$ & 0.9 & 4.6 & $<0.001$ \\
\hline
\end{tabular}

Table 2. Comparison between children included and excluded from the analysis due to missing beverage data (Numbers and percentages; mean values and standard deviations)

\begin{tabular}{|c|c|c|c|c|c|c|}
\hline \multirow[b]{2}{*}{ Characteristic } & \multirow[b]{2}{*}{ Subcategory } & \multicolumn{2}{|c|}{ Included children ( $n$ 1987) } & \multicolumn{2}{|c|}{ Excluded children ( $n$ 963) } & \multirow[b]{2}{*}{$P^{*}$} \\
\hline & & $n$ & $\%$ & $n$ & $\%$ & \\
\hline \multicolumn{6}{|l|}{ Age at baseline (years) } & 0.042 \\
\hline Mean & & \multirow{2}{*}{\multicolumn{2}{|c|}{$\begin{array}{l}8.28 \\
0.75\end{array}$}} & \multicolumn{2}{|c|}{$8 \cdot 34$} & \\
\hline SD & & & & \multicolumn{2}{|c|}{0.75} & \\
\hline Male & & 940 & $47 \cdot 3$ & 542 & $56 \cdot 3$ & $<0.001$ \\
\hline Migrational background & & 874 & 44.0 & 432 & 44.9 & 0.65 \\
\hline Intervention group & & 1070 & 53.9 & 571 & $59 \cdot 3$ & 0.005 \\
\hline BMI at baseline $\left(\mathrm{kg} / \mathrm{m}^{2}\right)$ & & & & & & 0.36 \\
\hline Mean & & \multicolumn{2}{|c|}{$17 \cdot 2$} & \multicolumn{2}{|c|}{$17 \cdot 3$} & \\
\hline SD & & \multirow{2}{*}{\multicolumn{2}{|c|}{$2 . \overline{9}$}} & \multicolumn{2}{|c|}{2.9} & \\
\hline Change in BMI $\left(\mathrm{kg} / \mathrm{m}^{2}\right)$ & & & & & & 0.059 \\
\hline Mean & & \multicolumn{2}{|c|}{0.38} & \multicolumn{2}{|c|}{0.43} & \\
\hline SD & & \multicolumn{2}{|c|}{0.74} & \multicolumn{2}{|c|}{0.76} & \\
\hline \multirow[t]{4}{*}{$\mathrm{BMI}$ category $\dagger$ at baseline } & & & & & & 0.99 \\
\hline & Normal weight & 1500 & $75 \cdot 5$ & 727 & 75.5 & \\
\hline & Overweight & 345 & 17.4 & 166 & $17 \cdot 2$ & \\
\hline & Obesity & 142 & $7 \cdot 1$ & 70 & $7 \cdot 3$ & \\
\hline \multirow{4}{*}{ BMI category $\dagger$ at follow-up } & & & & & & \multirow{4}{*}{0.61} \\
\hline & Normal weight & 1493 & $75 \cdot 1$ & 708 & 73.5 & \\
\hline & Overweight & 357 & $18 \cdot 0$ & 187 & $19 \cdot 4$ & \\
\hline & Obesity & 137 & $6 \cdot 9$ & 68 & $7 \cdot 1$ & \\
\hline
\end{tabular}

* Group differences tested by Wilcoxon's rank sum test for continuous variables and the $\chi^{2}$ test for categorical variables.

$\uparrow$ Categorised according to the recommendations of the International Obesity Task Force ${ }^{(35)}$.

for the total sample and for the subgroups if the tests for interaction reached significance. Each increase in water consumption by 1 glass/d led to a small reduction in the consumption of sugar-containing beverages, as well as in each of the subcategory soft drinks and juices, independent of BMI, baseline and change in consumption of all beverage categories, 


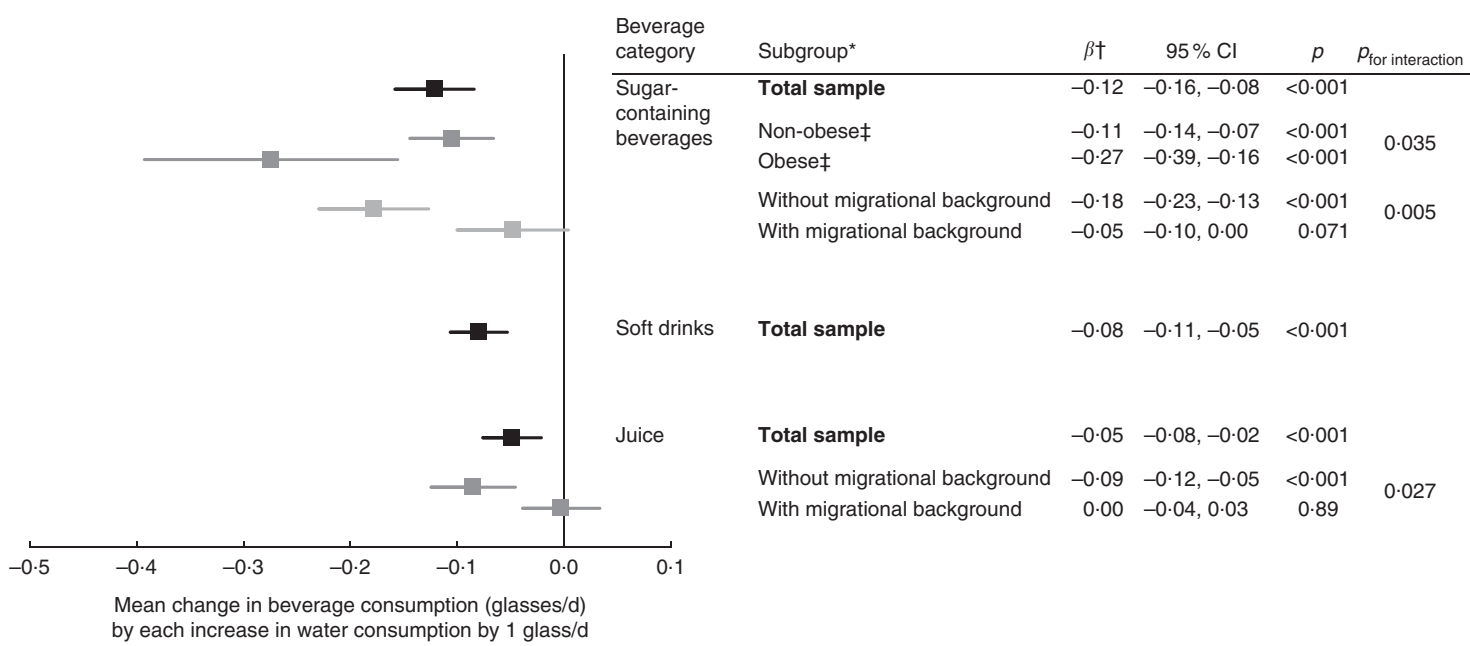

Fig. 1. Mean changes in the consumption of sugar-containing beverages and the subcategories soft drinks and juices (glasses/d) with $95 \% \mathrm{Cl}$ (indicated by error bars) by an increased water consumption of 1 glass/d from baseline to follow-up in the total sample $(n 1987)$ and in the subgroups. ${ }^{*}$ Subgroup analyses are shown if the interaction was significant with $P<0.05$. $† \beta$ Estimates are adjusted for baseline $\mathrm{BMI}$, baseline and change in consumption of all beverage categories, age, sex, migrational background, study arm and follow-up duration. $\ddagger$ Obesity was defined according to the recommendations of the International Obesity Task Force ${ }^{(35)}$.

age, sex, migrational background, study arm and follow-up duration (Fig. 1).

An analysis of interactions indicated that this association between increased water consumption and less intake of sugar-containing beverages was modified by the presence of obesity at baseline. The association was more pronounced in obese than in non-obese children. There was also a significant interaction with migrational background. An increase in water consumption was only associated with reduced consumption of sugar-containing beverages and juices in children without a migrational background but not in children with a migrational background (Fig. 1).

The effects of a change in water consumption, categorised in quintiles, on the change in consumption of sugar-containing beverages and the subcategories soft drinks and juices suggest that the associations were approximately linear (see online Supplementary Fig. S1). The change in consumption of sugarcontaining beverages and soft drinks differed between the quintiles of water consumption (both $P<0.001$ ) with largest reductions in their consumption in the 5 th quintile, which was defined as the highest increase in water consumption, compared with the 3rd quintile (reference), with no or low changes in consumption. In contrast, the effect on juice consumption did not reach statistical significance $(P=0 \cdot 070)$.

\section{Effect of water and beverage consumption on BMI}

Fig. 2 shows the within-subject effects of increases in beverage consumption by 1 glass/d on changes in BMI in the total sample and in the subgroups in the case of interaction. An increase in water consumption was not associated with a change in BMI. In contrast, each increase in the consumption of sugar-containing beverages by 1 glass/d led to a within-subject increase in BMI by $0.02(95 \%$ CI $0 \cdot 00,0.03) \mathrm{kg} / \mathrm{m}^{2}$. Analysing the subcategories soft drinks and juices separately, an increase in the consumption of soft drinks but not of juices was associated with an increase in BMI. There was a significant interaction of juice consumption with obesity, but subgroup analyses in non-obese and in obese children did not result in significant associations between increased juice consumption and changes in BMI (Fig. 2).

Analysing the effects of a change in beverage consumption, categorised in quintiles, on the change in BMI confirmed that there was no association with a change in the consumption of water $(P=0.99)$ but of sugar-containing beverages $(P=0.014)$ (see online Supplementary Fig. S2). Children who were in the 5 th quintile, that is who had the highest increase in sugarcontaining beverage consumption, had on average an increase in BMI of $0.16(95 \%$ CI $0.06,0.25) \mathrm{kg} / \mathrm{m}^{2}$ compared with children in the 3rd quintile (reference) who had no or a low increase in the consumption of sugar-containing beverages. The effect of a change in soft drink consumption, categorised in quintiles, on BMI did not reach significance $(P=0.057)$, but the effect estimates of the quintiles suggest linearity of the association: The estimated mean increases in BMI increased with higher soft drink consumption, categorised in the quintiles. There was no association between quintiles of change in juice consumption and change in BMI $(P=0.82)$ (see online Supplementary Fig. S2).

\section{Effect of water and beverage consumption on overweight and obesity}

Fig. 3 shows the OR of the prevalence of overweight (including obesity) and obesity at follow-up for each increase in beverage consumption by 1 glass/d. There was no significant association between changes in the consumption of any beverage and the prevalence of overweight. In contrast, each increase in sugarcontaining beverage consumption by 1 glass/d increased the likelihood for obesity at follow-up (OR 1.22; $95 \%$ CI 1.04, 1.44). Analysing the subcategories soft drinks and fruit juices 


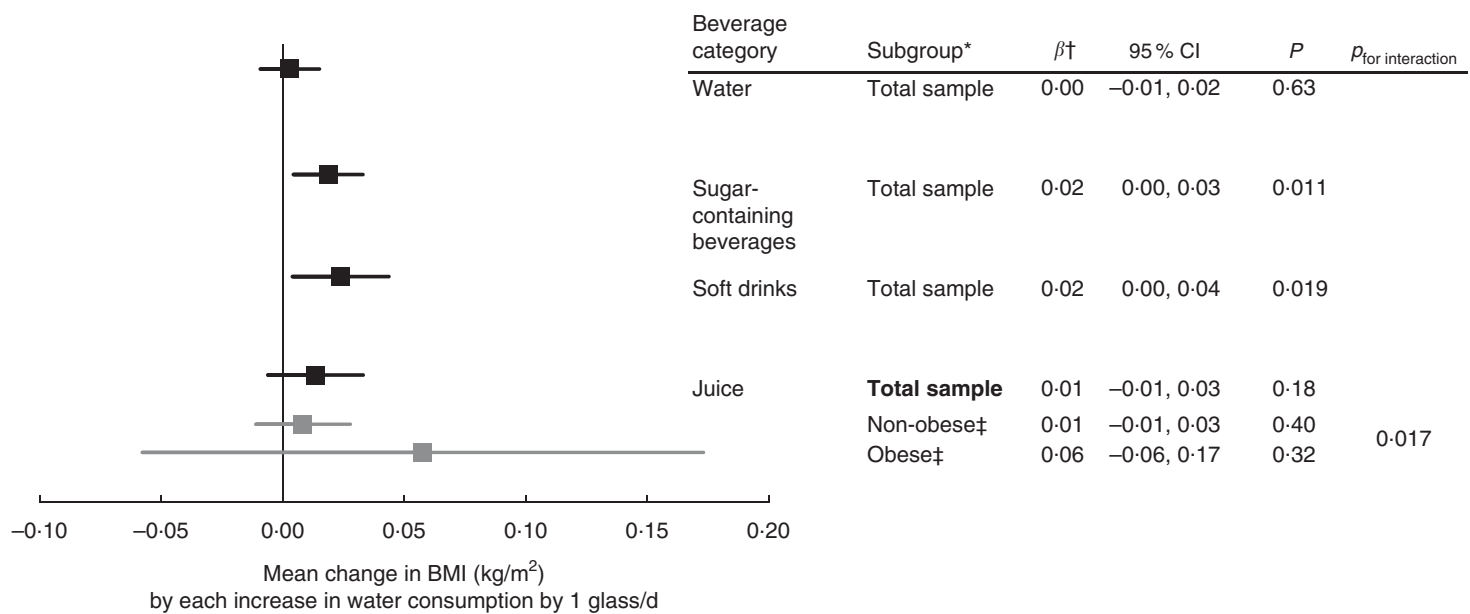

Fig. 2. Mean changes in $\mathrm{BMl}\left(\mathrm{kg} / \mathrm{m}^{2}\right)$ with $95 \% \mathrm{Cl}$ (indicated by error bars) by an increased consumption of water, sugar-containing beverages and the subcategories soft drinks and juices by 1 glass/d from baseline to follow-up in the total sample $(n 1987)$ and in the subgroups. * Subgroup analyses are shown if interaction was significant with $P<0.05$. $† \beta$ Estimates are adjusted for BMl and consumption of all beverage categories at baseline, change in milk, tea and other beverages consumption, age, sex, migrational background, study arm and follow-up duration. $\ddagger$ Overweight (including obesity) and obesity defined according to the recommendations of the International Obesity Task Force ${ }^{(35)}$.

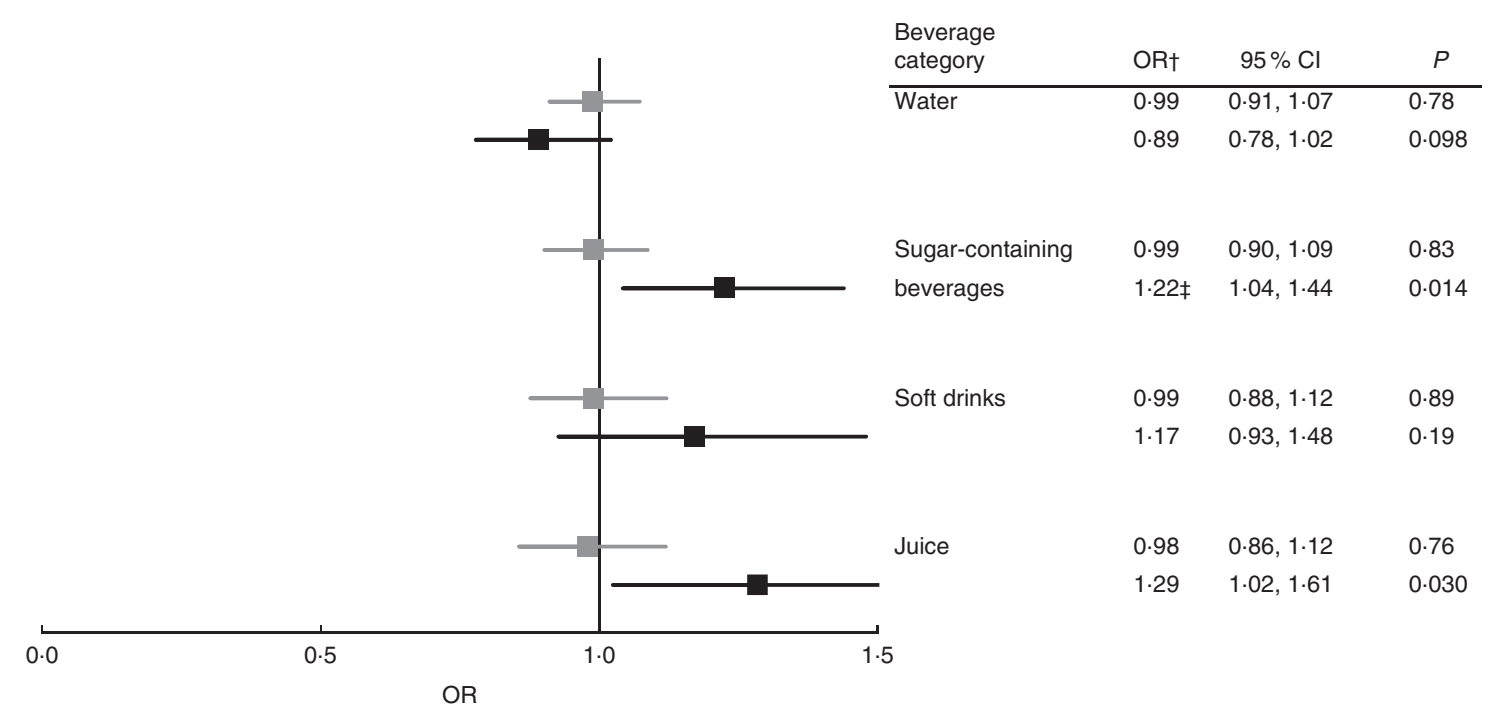

Fig. 3. OR for the prevalence of overweight (including obesity) and obesity at follow-up with $95 \% \mathrm{Cl}$ (indicated by error bars) for an increased consumption of water, sugar-containing beverages and the subcategories soft drinks and juices by 1 glass/d from baseline to follow-up ( $n$ 1987). $\square$, obesity* . ${ }^{*}$ Defined according to the recommendations of the International Obesity Task Force ${ }^{(35)}$. $†$ OR are adjusted for baseline BMI, baseline consumption of all beverage categories, change in milk, tea and other beverages consumption, age, sex, migrational background, study arm and follow-up duration. $\ddagger$ In the mixed-effects models, an unstructured covariance structure instead of the compound-symmetry was used to enable the model to converge.

separately, an increase in juice but not in soft drink consumption was associated with the prevalence of obesity at follow-up.

To test the robustness of the logistic models on the effects, in a second model, we adjusted for baseline prevalence of overweight (including obesity) and obesity, respectively, instead of baseline BMI. The results differed as the effects of sugar-containing beverage and juice consumption on the prevalence of obesity were only significant in the model adjusting for BMI but not significant anymore in the model adjusting for obesity $(P=0.06$ and 0.25$)$ (see Supplementary Fig. S3).

\section{Discussion}

In this secondary analysis, we examined longitudinal data from an intervention study that promoted water consumption for overweight prevention in schoolchildren. We combined intervention and control group data to investigate the associations between individual (within-subject) changes in beverage consumption and weight development over a mean follow-up of 8 months. A direct effect of changed water consumption on body weight development was not observed. However, there was evidence that increased water consumption was associated with decreases in sugar-containing 
beverage consumption. In addition, increased sugar-containing beverage consumption was associated with increases in BMI.

The analyses did not show that increased water consumption itself directly affected body weight outcomes. According to a systematic review ${ }^{(23)}$, three longitudinal observational analyses have investigated the association between baseline water consumption and subsequent changes in body weight outcomes in children ${ }^{(28-30)}$, but none has investigated the effect of a change in water consumption on body weight outcomes. A recent analysis in pre-school children also did not find an association between a change in water consumption and changes in body weight outcomes during a follow-up of 1.5 years $^{(37)}$. In adults, Pan et $a l^{(38)}$ analysed the effect of a change in water consumption in pooled data from large US cohorts with a long-term follow-up of 16-20 years. They found that increased water consumption was associated with reduced weight gain by $0.13(95 \% \mathrm{CI}-0 \cdot 17,-0 \cdot 18) \mathrm{kg}$ in 4 years for each additional serving of water. This association was adjusted for baseline BMI and changes in intake of other beverages as well as in lifestyle factors such as smoking behaviour, diet and physical activity, which we could not control for in our analysis. Physical activity, for example, could have confounded our analysis as it is associated with water consumption as well as body weight outcomes in children at least in the cross-sectional level ${ }^{(39)}$. However, Pan et al. ${ }^{(38)}$ did not investigate whether changes in other beverages such as sugar-containing beverages could be responsible for the association between water consumption and weight gain.

The replacement of sugar-containing beverages by increased water consumption is a suggested mechanism for a beneficial effect of water consumption on body weight measures. In order to estimate the total and not only the direct effect of water consumption on body weight outcomes, we analysed data without controlling for changes in sugar-containing beverage consumption. There was no total effect of water consumption on BMI. The association between change in water consumption and sugar-containing beverages was small, with a reduced consumption of 0.12 glasses per 1 additional glass of water/d. This might be a reason why a total effect of water on BMI was not observed. Another potential reason for the lack of association of increased water consumption with reduced BMI could be due to a measurement error in the self-reported beverage consumption among the young children. Random measurement error tend to attenuate regression coefficients.

An additional reason for a missing effect of water on BMI could be that not only water consumption may affect BMI but also vice versa: an increased BMI might lead to increased water consumption. Several studies in children showed that on the cross-sectional level a higher BMI and obesity were associated with higher water consumption ${ }^{(23)}$. A reason for this could be higher fluid needs in obese children due to increased salt or protein intakes. In children, total fluid and water consumption were directly associated with salt and $\mathrm{Na}$ intakes ${ }^{(40,41)}$, and salt and $\mathrm{Na}$ intakes increased with higher $\mathrm{BMI}^{(42,43)}$.

A suggested mechanism for weight reduction through the replacement of sugar-containing beverages with water is the reduction in energy intake that is not compensated for by increased consumption of other energy-containing foods or beverages. Two studies calculated the reduction in total energy intake if sugar-sweetened beverage consumption was completely replaced by water. In the US child population, Wang et al. ${ }^{(44)}$ estimated from two 24-h recalls within $10 \mathrm{~d}$ the hypothetic amount of $983 \mathrm{~kJ} / \mathrm{d}(235 \mathrm{kcal} / \mathrm{d})$ that could be saved by a complete replacement. In adults, a similarly calculated reduction in total energy intake of $837 \mathrm{~kJ} / \mathrm{d}(200 \mathrm{kcal} / \mathrm{d})$ over 12 months was estimated ${ }^{(45)}$. Zheng et al. ${ }^{(37)}$ calculated in a statistical replacement model that in pre-school children the substitution of sugary drinks with the same amount of diet drinks resulted in reduced weight but not the substitution with water.

As soft drinks and juices often have similar sugar and energy contents, their effects on weight gain through increased energy intake are suggested to be the same. However, in our analyses, increasing soft drink consumption by 1 glass/d increased BMI by $0.02 \mathrm{~kg} / \mathrm{m}^{2}$, whereas there was no significant association of changes in juice consumption with change in BMI. On the other hand, our data indicated that obesity was associated with an increased juice but not soft drink consumption, although the findings were not very robust. The association between increased juice consumption and obesity was only significant in the model adjusting for baseline BMI but not when adjusting for obesity prevalence. Analyses of quintiles suggested that the association with obesity might not be linear and only substantial increases in juice consumption increased the risk of obesity. Other studies that investigated the effects of both soft drinks and juices on body weight outcomes yielded inconsistent results. Libuda et al. ${ }^{(46)}$ showed that in German female adolescents increasing juice consumption led to an even greater weight gain compared with soft drinks. In US adults, increased juice consumption was shown to be associated with weight gain but to a lower extent compared with sugar-sweetened beverages $^{(38,47)}$.

Even if the obesogenic effect of soft drinks and juices may not be the same, the replacement potential probably depends on cultural and dietary habits as well. In the present German children sample, the amounts of soft drink and juice consumption were almost equal, which is in contrast to the dietary habits of US children, whose consumption of soft drinks and other sugar-sweetened beverages is about double the fruit juice consumption ${ }^{(48)}$. In addition, our data indicated that increased water consumption replaced the consumption of both soft drinks and juices, although only to a small extent: the replacement of juices by 0.05 glasses/glass of water was slightly lower than the replacement of soft drinks ( 0.08 glasses). Thus, the potential effect of the replacement of sugar-containing beverages with water might differ between populations.

The data of this secondary analysis were derived from an intervention study that aimed at the prevention of overweight through the promotion of water consumption ${ }^{(32)}$. The hypothesis was that water would replace sugar-containing beverages, and thereby prevent excessive weight gain. The intervention reduced the prevalence of overweight in the intervention compared with the control group. Water consumption was 1 glass/d higher in the intervention than in the control group, but the reduction in juice and soft drink 
consumption did not reach statistical significance. The present analysis, however, supports the hypothesis that the observed intervention effect on the prevalence of overweight might be caused by the replacement of sugar-containing beverages with water. Increases in sugar-containing beverages were also shown to be associated with increases in BMI in the study population. Another mechanism for the intervention effect could be that the intervention might have changed other obesity-associated behaviours affecting the energy balance, which were not considered in the analysis. Such behaviours could be other dietary factors or physical activity, which were shown to be associated with water intake in children ${ }^{(40,49)}$.

Our data indicated that water replaced sugar-containing beverages only in children without a migrational background but not in children with a migrational background. This could explain why the intervention promoting drinking water, which was investigated in the intervention study, was shown to be effective only in children without a migrational background ${ }^{(34)}$. Plausible explanations why the promotion of drinking water was less successful in children with a migrational background might be found in culturally dependent dietary habits. In the study population ${ }^{(34)}$ as well as in the German population ${ }^{(50)}$, children differ in water, soft drink and juice consumption by their migrational background. In addition, children with migrational background have an increased risk for overweight and obesity ${ }^{(51)}$.

\section{Strengths and limitations}

This analysis included longitudinal data on beverage consumption and measured BMI of 1987 children. Beverage consumption was assessed at baseline and prospectively after an 8-month follow-up. Thus, we were able to calculate the predictive association between baseline beverage consumption and body weight development as well as to estimate the effects of individual changes in dietary behaviour on individual changes in body weight outcomes by the 'change-on-change' analysis. A major limitation of this analysis is that the detected association between increased sugar-containing beverage consumption and BMI was quite small. Owing to this small effect, it was rare that a child's BMI category changed. This might explain why changes in beverage consumption did not affect prevalence of overweight at all and the prevalence of obesity only depending on the adjustment model. Another limitation was the validity of the 24-h recall beverage questionnaire. Although self-reporting in children of elementary school age is possible, it is restricted because of the cognitive abilities of children ${ }^{(52)}$. The relative validation of the $24-\mathrm{h}$ recall against a 24-h weighed record showed that the volume of soft drink consumption was overestimated by a higher amount compared with juices ${ }^{(36)}$. In the present population, the total self-reported beverage consumption at baseline was 8 glasses/ $\mathrm{d}$, which equals $1600 \mathrm{ml} / \mathrm{d}$ assuming the predefined volume of $200 \mathrm{ml} /$ glass. This also points towards an overestimation of the consumption by the 24-h recall, because a German survey showed the mean beverage consumption (excluding milk) to be approximately $900 \mathrm{ml} / \mathrm{d}$ in this age group ${ }^{(53)}$. According to the validation study, the ability to differentiate between beverage categories was limited as well. For example, $13 \%$ of children misclassified soft drinks as juices in the validation study $^{(36)}$. In addition, the category 'juices' also included fruit drinks, and therefore did not distinguish drinks with a small percentage of juice from $100 \%$ fruit juices. Thus, in the analyses, we also combined soft drinks and juices in the category 'sugar-containing beverages' to reduce this misclassification effect. Another limitation is that the analyses were not adjusted for energy intake, food consumption and physical activity. Thus, compensational mechanisms or effects of changed beverage consumption on other behavioural factors and on the energy balance as potential confounders were not investigated. A reporting bias in the assessment of beverage consumption is also possible, because participants in the intervention promoting water consumption were not blinded. This could induce over-reporting of water consumption as well as under-reporting of sugar-containing beverages in children of the intervention group due to social desirability. Being in the intervention group itself could have a beneficial effect on behaviour and outcome independent of the implementation of the intervention measure. To control for this, we adjusted all analyses for the study arm and investigated whether the associations were thereby modified. The interaction analyses showed that the analysed effects did not differ between the intervention and control group.

\section{Conclusion}

Water consumption was not shown to have a direct beneficial effect on body weight outcomes, but water could replace the consumption of sugar-containing beverages to some extent. This replacement may be a pathway for increased water consumption to prevent weight gain, because sugar-containing beverages were shown to have an adverse effect on body weight. Not all populations may benefit equally from increased water consumption with respect to replacement of sugar-containing beverages, such as children with a migrational background. However, the recommendation of water consumption to replace sugar-containing beverages can still be supported.

\section{Acknowledgements}

This secondary analysis received no specific grant from any funding agency, commercial or not-for-profit sectors. The original intervention study was conducted at the Research Institute of Child Nutrition Dortmund (Dortmund, Germany) and was supported by grant no. 05HS026 from the German Federal Ministry of Food, Agriculture and Consumer Protection. Intervention materials were provided by the Association of the German Gas and Water Industries. Both funders had no role in the design, analysis or writing of this article.

The authors' contributions are as follows: R. M., S. L. G. and J. M.-N. formulated the research question. R. M., L. L., M. K., B. A. contributed to the study design. R. M., L. L. and K. C. contributed to data collection. R. M. carried out data analyses and wrote the article. L. L. and S. L. G. contributed to data 
analyses. All the authors contributed to the interpretation of the findings and read and approved the final version of the article.

R. M. received speaker grants from Danone Research, France, in 2010-2012. All other authors declared no conflicts of interest.

\section{Supplementary material}

For supplementary material/s referred to in this article, please visit http://dx.doi.org/10.1017/S0007114516001136

\section{References}

1. Popkin BM, Armstrong LE, Bray GM, et al. (2006) A new proposed guidance system for beverage consumption in the United States. Am J Clin Nutr 83, 529-542.

2. US Department of Agriculture \& US Department of Health and Human Services (2010) Dietary Guidelines for Americans, 7th ed. Washington, DC: U.S. Government Printing Office.

3. Health Canada (2001) Canada's Food Guide. http://www. hc-sc.gc.ca/fn-an/alt_formats/hpfb-dgpsa/pdf/food-guide-aliment/ view_eatwell_vue_bienmang-eng.pdf (accessed June 2014).

4. Kersting M, Alexy U \& Clausen K (2005) Using the concept of Food Based Dietary Guidelines to Develop an Optimized Mixed Diet (OMD) for German children and adolescents. J Pediatr Gastroenterol Nutr 40, 301-308.

5. US Department of Health and Human Services \& The US Department of Agriculture (2015) Dietary Guidelines for Americans. 2015-2020, 8th ed. Washington, DC: US Department of Health and Human Service and US Department of Agriculture. http://health.gov/dietaryguidelines/2015/ guidelines/ (accessed January 2016).

6. European Association for the Study on Obesity \& Healthy Hydration Working Group (2015) Drink water be healthy. http://gucdv1wwi8pslzdfpv7t0dk6.wpengine.netdna-cdn.com/ wp-content/uploads/2015/09/EASO_hydration-tips_HCPs_HD_ final.pdf (accessed October 2015).

7. American Medical Association (AMA) (2012) AMA Healthier Life Steps®IA patient-physician partnership for a longer, healthier life. Action plan for healthy eating. http:// www.nwsphysicians.com/web/wp-content/uploads/2014/01/ AMA-Healthy-Eating.pdf (accessed January 2016).

8. Department of Health, Australian Government (2015) Water. The original cool drink. Campaign action sheet primary schools. https://www.marion.sa.gov.au/webdata/ resources/files/OPAL-Water-CAS-Primary-Schools.pdf (accessed January 2016).

9. Must A, Barish EE \& Bandini LG (2009) Modifiable risk factors in relation to changes in BMI and fatness: what have we learned from prospective studies of school-aged children? Int J Obes (Lond) 33, 705-715.

10. Malik VS, Pan A, Willett WC, et al. (2013) Sugar-sweetened beverages and weight gain in children and adults: a systematic review and meta-analysis. Am J Clin Nutr $\mathbf{9 8}$, 1084-1102.

11. Te Morenga L, Mallard S \& Mann J (2013) Dietary sugars and body weight: systematic review and meta-analyses of randomised controlled trials and cohort studies. BMJ $\mathbf{3 4 6}$, e7492.

12. Hu FB (2013) Resolved: there is sufficient scientific evidence that decreasing sugar-sweetened beverage consumption will reduce the prevalence of obesity and obesity-related diseases. Obes Rev 14, 606-619.
13. World Health Organization (2003) Diet, Nutrition and the Prevention of Chronic Diseases. Joint WHO/FAO Expert Consultation. WHO Technical Report Series no. 916. Geneva: WHO.

14. Gidding SS, Dennison BA, Birch LL, et al. (2006) Dietary recommendations for children and adolescents: a guide for practitioners. Pediatrics 117, 544-559.

15. Ernährungskommission der Deutschen Gesellschaft für Kinder- und Jugendmedizin DGKJ, Ernährungskommission der Österreichischen Gesellschaft für Kinder- und Jugendheilkunde ÖGKJ, Ernährungskommission der Schweizerischen Gesellschaft für Pädiatrie SGP (2008) Empfehlungen zum Verzehr zuckerhaltiger Getränke durch Kinder und Jugendliche (Recommendations on the consumption of sugar-containing beverages in children and adolescents). Monatsschr Kinderbeilkd 156, 484-487.

16. American Academy of Pediatrics (2001) The use and misuse of fruit juice in pediatrics. Pediatrics 107, 1210-1213.

17. Daniels MC \& Popkin BM (2010) Impact of water intake on energy intake and weight status: a systematic review. Nutr Rev 68, 505-521

18. Dennis EA, Flack KD \& Davy BM (2009) Beverage consumption and adult weight management: A review. Eat Behav 10, 237-246.

19. Stookey JJ (2016) Negative, null and beneficial effects of drinking water on energy intake, energy expenditure, fat oxidation and weight change in randomized trials: a qualitative review. Nutrients $\mathbf{8}, 19$.

20. Cecil JE, Palmer CN, Wrieden W, et al. (2005) Energy intakes of children after preloads: adjustment, not compensation. Am J Clin Nutr 82, 302-308.

21. Birch LL, McPhee L \& Sullivan S (1989) Children's food intake following drinks sweetened with sucrose or aspartame: time course effects. Physiol Behav 45, 387-395.

22. Muckelbauer R, Sarganas G, Gruneis A, et al. (2013) Association between water consumption and body weight outcomes: a systematic review. Am J Clin Nutr 98, 282-299.

23. Muckelbauer R, Barbosa CL, Mittag T, et al. (2014) Association between water consumption and body weight outcomes in children and adolescents: a systematic review. Obesity (Silver Spring) 22, 2462-2475.

24. Dennis EA, Dengo AL, Comber DL, et al. (2010) Water consumption increases weight loss during a hypocaloric diet intervention in middle-aged and older adults. Obesity (Silver Spring) 18, 300-307.

25. Stookey JD, Constant F, Popkin BM, et al. (2008) Drinking water is associated with weight loss in overweight dieting women independent of diet and activity. Obesity (Silver Spring) 16, 2481-2488.

26. Akers JD, Cornett RA, Savla JS, et al. (2012) Daily self-monitoring of body weight, step count, fruit/vegetable intake, and water consumption: a feasible and effective long-term weight loss maintenance approach. J Acad Nutr Diet 112, 685-692.

27. Parretti HM, Aveyard P, Blannin A, et al. (2015) Efficacy of water preloading before main meals as a strategy for weight loss in primary care patients with obesity: RCT. Obesity (Silver Spring) 23, 1785-1791.

28. Dubuisson AC, Zech FR, Dassy MM, et al. (2012) Determinants of weight loss in an interdisciplinary long-term care program for childhood obesity. ISRN Obesity 2012, 349384.

29. Sichieri R, Yokoo EM, Pereira RA, et al. (2013) Water and sugar-sweetened beverage consumption and changes in BMI among Brazilian fourth graders after 1-year follow-up. Public Health Nutr 16, 73-77.

30. Johnson L, Mander AP, Jones LR, et al. (2007) Is sugarsweetened beverage consumption associated with increased fatness in children? Nutrition 23, 557-563. 
31. Schwartz AE, Leardo M, Aneja S, et al. (2016) Effect of a school-based water intervention on child body mass index and obesity. JAMA Pediatr 170, 220-226.

32. Muckelbauer R, Libuda L, Clausen K, et al. (2009) Promotion and provision of drinking water in schools for overweight prevention: randomized, controlled cluster trial. Pediatrics 123, e661-e667.

33. Muckelbauer R, Libuda L, Clausen K, et al. (2009) Long-term process evaluation of a school-based programme for overweight prevention. Child Care Health Dev 35, 851-857.

34. Muckelbauer R, Libuda L, Clausen K, et al. (2010) Immigrational background affects the effectiveness of a school-based overweight prevention program promoting water consumption. Obesity (Silver Spring) 18, 528-534.

35. Cole TJ, Bellizzi MC, Flegal KM, et al. (2000) Establishing a standard definition for child overweight and obesity worldwide: international survey. BMJ 320, 1240-1243.

36. Muckelbauer R, Libuda L \& Kersting M (2010) Relative validity of a self-completion $24 \mathrm{~h}$ recall questionnaire to assess beverage consumption among schoolchildren aged 7 to 9 years. Public Health Nutr 13, 187-195.

37. Zheng M, Rangan A, Allman-Farinelli M, et al. (2015) Replacing sugary drinks with milk is inversely associated with weight gain among young obesity-predisposed children. Br J Nutr 114, 1448-1455.

38. Pan A, Malik VS, Hao T, et al. (2013) Changes in water and beverage intake and long-term weight changes: results from three prospective cohort studies. Int J Obes (Lond) 37, 1378-1385.

39. Kant AK \& Graubard BI (2010) Contributors of water intake in US children and adolescents: associations with dietary and meal characteristics - National Health and Nutrition Examination Survey 2005-2006. Am J Clin Nutr 92, 887-896.

40. Lee HS, Park S \& Kim MH (2014) Factors associated with low water intake among South Korean adolescents Korea National Health and Nutrition Examination Survey, 2007-2010. Nutr Res Pract 8, 74-80.

41. Grimes CA, Riddell LJ, Campbell KJ, et al. (2013) Dietary salt intake, sugar-sweetened beverage consumption, and obesity risk. Pediatrics 131, 14-21.

42. Libuda L, Kersting M \& Alexy U (2012) Consumption of dietary salt measured by urinary sodium excretion and its association with body weight status in healthy children and adolescents. Public Health Nutr 15, 433-441.
43. Yoon YS \& Oh SW (2013) Sodium density and obesity; the Korea National Health and Nutrition Examination Survey 2007-2010. Eur J Clin Nutr 67, 141-146.

44. Wang YC, Ludwig DS, Sonneville K, et al. (2009) Impact of change in sweetened caloric beverage consumption on energy intake among children and adolescents. Arch Pediatr Adolesc Med 163, 336-343.

45. Stookey JD, Constant F, Gardner CD, et al. (2007) Replacing sweetened caloric beverages with drinking water is associated with lower energy intake. Obesity (Silver Spring) 15 , 3013-3022.

46. Libuda L, Alexy U, Sichert-Hellert W, et al. (2008) Pattern of beverage consumption and long-term association with body-weight status in German adolescents - results from the DONALD study. BrJ Nutr 99, 1370-1379.

47. Mozaffarian D, Hao T, Rimm EB, et al. (2011) Changes in diet and lifestyle and long-term weight gain in women and men. $N$ Engl J Med 364, 2392-2404.

48. Slining MM, Mathias KC \& Popkin BM (2013) Trends in food and beverage sources among US children and adolescents: 1989-2010. J Acad Nutr Diet 113, 1683-1694.

49. Park S, Blanck HM, Sherry B, et al. (2012) Factors associated with low water intake among US high school students National Youth Physical Activity and Nutrition Study, 2010. J Acad Nutr Diet 112, 1421-1427.

50. Mensink GB, Kleiser C \& Richter A (2007) [Food consumption of children and adolescents in Germany. Results of the German Health Interview and Examination Survey for Children and Adolescents (KiGGS)]. Bundesgesundheitsblatt Gesundheitsforschung Gesundheitsschutz 50, 609-623.

51. Kurth BM \& Schaffrath Rosario A (2007) [The prevalence of overweight and obese children and adolescents living in Germany. Results of the German Health Interview and Examination Survey for Children and Adolescents (KiGGS)]. Bundesgesundheitsblatt Gesundheitsforschung Gesundheitsschutz 50, 736-743.

52. Livingstone MB \& Robson PJ (2000) Measurement of dietary intake in children. Proc Nutr Soc 59, 279-293.

53. Mensink G, Heseker H, Richter A, et al. (2007) Forschungsbericht Ernährungs studie als KiGGS-Modul (EsKiMo) (Research Report Eating Study (EsKiMo) as a KiGGS Module). https://www.bmel.de/SharedDocs/Downloads/Ernaehrung/ EsKiMoStudie.pdf?_blob=publicationFile (accessed March 2016). 